\author{
Ann C. Long \\ J. Randall Curtis
}

\section{Quality of dying in the ICU: understanding ways to make it better}

Accepted: 27 September 2014

Published online: 7 October 2014

(C) Springer-Verlag Berlin Heidelberg and ESICM 2014

Dear Editor,

We appreciate the comments on our work from Gifford and Esquinas [1]. We believe that our study [2] adds to the field by identifying patients arriving to the ICU from the hospital ward as a group at high risk for poor quality palliative and end-of-life care. The factors influencing the association between ICU admission from the hospital ward and lower family ratings of care and quality of dying are likely myriad and complex. As Gifford and Esquinas point out, patients arriving from the hospital ward may differ from patients admitted to the ICU from the emergency department in a number of important ways. The length of time spent on the hospital ward, the patient's admitting diagnosis, and the characteristics surrounding transfer to the ICU all likely contribute to family member expectations for their loved one's care. These factors are important considerations when assuming the care of patients arriving in the ICU from the hospital ward, and more research is needed to understand how these various factors might influence family member experiences.

We agree that it is concerning that for both groups of patients, discussions of prognosis were documented so infrequently, particularly because all patients in this cohort died. The reasons why the family members of patients from the hospital ward were less likely to have family conferences or discussions of prognosis documented in the first $72 \mathrm{~h}$ of ICU admission are unclear and this important finding warrants further investigation. Although some may argue that family members of patients arriving from the emergency department require more intensive communication, it seems difficult to support this notion given the severity of illness observed in patient's arriving to the ICU from the hospital ward $[3,4]$. Even if conferences for family of patients arriving from the emergency department were believed to be more pressing, it seems unreasonable that family of patients admitted from the hospital ward should wait more than 3 days to have a family conference. We also agree that a focus on improving transitions in care is warranted. Assessment of rapid response teams in decisions surrounding inpatient transfers suggests that even in time-sensitive situations, clinicians can still incorporate family in medical decision-making [5]. Transitions in care represent important events for hospitalized patients and their family, and a better understanding of barriers to high-quality transitions is needed to inform interventions to improve the quality of care provided to these critically ill patients and their family.

Conflicts of interest The authors have no financial conflict of interest.

\section{References}

1. Gifford AH, Esquinas AM (2014) Quality of dying in the intensive care unit: it's a matter of time. Intensive Care Med. doi:10.1007/s00134-014-3499-x

2. Long AC, Kross EK, Engelberg RA, Downey L, Nielsen EL, Back AL, Curtis JR (2014) Quality of dying in the ICU: is it worse for patients admitted from the hospital ward compared to those admitted from the emergency department? Intensive Care Med. doi: 10.1007/s00134-014-3425-2

3. Hillman KM, Bristow PJ, Chey T, Daffurn K, Jacques T, Norman SL, Bishop GF, Simmons G (2002) Duration of life-threatening antecedents prior to intensive care admission. Intensive Care Med 28:1629-1634

4. Delgado MK, Liu V, Pines JM, Kipnis P, Gardner MN, Escobar GJ (2013) Risk

factors for unplanned transfer to intensive care within 24 hours of admission from the emergency department in an integrated healthcare system. J Hosp Med 8:13-19

5. Downar J, Rodin D, Barua R, Lejnieks B, Gudimella R, McCredie V, Hayes C, Steel A (2013) Rapid response teams, do not resuscitate orders, and potential opportunities to improve end-of-life care: a multicentre retrospective study. J Crit Care 28:498-503

A. C. Long · J. R. Curtis (

Division of Pulmonary and Critical Care Medicine, Department of Medicine, Harborview Medical Center,

University of Washington,

Seattle, WA, USA

e-mail: jrc@u.washington.edu 